\title{
CHANGES IN DEFENSIVE FUNCTIONING IN COMPLETED \\ PSYCHOANALYSES: \\ THE PENN PSYCHOANALYTIC TREATMENT COLLECTION
}

\author{
Carmella A. Roy, M.D. \\ Department of Psychiatry, Faculty of Medicine \\ McGill University, Montreal \\ December, 2003
}

Copyright $\odot$ Carmella Roy 2004

\begin{abstract}
A thesis submitted to the Faculty of Graduate Studies and Research, McGill University, in partial fulfillment of the requirements of the degree of: Master of Science in Psychiatry.
\end{abstract}

Sir Mortimer B. Davis-Jewish General Hospital

Department of Psychiatry, Office A-540

3755 Chemin de la Cote-Ste.-Catherine, Montreal, QC, H3T-1E2

tel: (514) 340-8222 (5897), fax: (514) 340-8126, email: carmella.roy@mcgill.ca 


$\begin{array}{ll}\begin{array}{l}\text { Library and } \\ \text { Archives Canada }\end{array} & \begin{array}{l}\text { Bibliothèque et } \\ \text { Archives Canada }\end{array} \\ \begin{array}{l}\text { Published Heritage } \\ \text { Branch }\end{array} & \begin{array}{l}\text { Direction du } \\ \text { Patrimoine de l'édition }\end{array} \\ \begin{array}{l}\text { 395 Wellington Street } \\ \text { Ottawa ON K1A 0N4 }\end{array} & \begin{array}{l}\text { 395, rue Wellington } \\ \text { Ottawa ON K1A ON4 } \\ \text { Canada }\end{array} \\ \end{array}$

Your file Votre référence ISBN: 0-612-98733-7

Ourfile Notre référence

ISBN: 0-612-98733-7

NOTICE:

The author has granted a nonexclusive license allowing Library and Archives Canada to reproduce, publish, archive, preserve, conserve, communicate to the public by telecommunication or on the Internet, loan, distribute and sell theses worldwide, for commercial or noncommercial purposes, in microform, paper, electronic and/or any other formats.

The author retains copyright ownership and moral rights in this thesis. Neither the thesis nor substantial extracts from it may be printed or otherwise reproduced without the author's permission.
AVIS:

L'auteur a accordé une licence non exclusive permettant à la Bibliothèque et Archives Canada de reproduire, publier, archiver, sauvegarder, conserver, transmettre au public par télécommunication ou par l'Internet, prêter, distribuer et vendre des thèses partout dans le monde, à des fins commerciales ou autres, sur support microforme, papier, électronique et/ou autres formats.

L'auteur conserve la propriété du droit d'auteur et des droits moraux qui protège cette thèse. $\mathrm{Ni}$ la thèse ni des extraits substantiels de celle-ci ne doivent être imprimés ou autrement reproduits sans son autorisation.
In compliance with the Canadian

Privacy Act some supporting forms may have been removed from this thesis.

While these forms may be included in the document page count, their removal does not represent any loss of content from the thesis.
Conformément à la loi canadienne sur la protection de la vie privée, quelques formulaires secondaires ont été enlevés de cette thèse.

Bien que ces formulaires aient inclus dans la pagination, il n'y aura aucun contenu manquant. 


\section{ACKNOWLEDGEMENTS}

I wish to thank my thesis supervisor and research mentor, Dr. J. Christopher Perry, for his invaluable support and scientific contributions to this project, from the initial planning, to the data analysis and the manuscript editing. I wish to thank Dr. Lester Luborsky who provided the data-set of the Penn Collection, and allowed us to use some of his results for comparison purposes. I wish to thank Dr. Elisabeth Banon who jointly conducted the reliability study. I also wish to thank Ms. Daisie Louie who photocopied, randomized and blinded the transcripts.

Special thanks to the Analytic Research Group of the Institute of Pennsylvania Hospital for recording most of the cases in the collection. Partial support for assembling the collection, for its transcription, and for the clinical analysis of the "general functioning" in the early and late sessions by two independent clinicians was provided by the Fund for Psychoanalytic Research of the American Psychoanalytic Association, from November 1, 1995 to October 31, 1997. Partial support was also provided by NIDA Research Scientist DA-0016823A, 24, 25, as well as NIMH MH 40710-22 (to Lester Luborsky) and Clinical Research Grant P $50 \mathrm{MH} 45178$ (to Paul Crits-Cristoph). Presented at the Collaborative Analytic Multi-site Program (CAMP) (Robert Wallerstein, director) at the American Psychoanalytic Association meeting December $19^{\text {th }}, 1997$. Partial support, provided by CAMP, allowed the transcription of an additional 60 sessions that 
were subsequently rated for defense mechanisms, and added to the sample.

Support has also been provided by the American Psychoanalytic Foundation, Harvey Rich, director. 


\section{CONTRIBUTIONS}

Dr. Roy did the literature review, rated the defense mechanisms for the majority $(>85 \%)$ of the transcripts, took part in all the consensus ratings, participated in the data-programming, data-entry and data-analysis. In addition, she wrote all the drafts of the paper, after attending all the meetings that were held to discuss the conceptualization, the methodology, and the data-analysis of the project.

Dr. Perry attended all the meetings that were held to discuss the methodology, the data-analysis, and the development of the project. He participated in the data-programming, data-entry and data-analysis. He proofread and provided feedback on all the drafts of the paper. He also participated in a few consensus ratings.

Dr. Luborsky made available the Penn Collection data set to our team, he made available his previous results on the same data-set, and he proofread and provided feedback on the first draft of the paper.

Dr. Banon took part in majority of the consensus ratings, and proofread and provided feedback on the first draft of the paper. 


\section{TABLE OF CONTENTS}

TABLE OF CONTENTS

p. 5

LIST OF TABLES

p. 6

ABSTRACT

p. 7

RESUME (FRENCH)

p. 8

INTRODUCTION \& REVIEW OF THE LITERATURE

p. 9

Recent Research in Psychoanalysis and Psychoanalytic

Psychotherapy

p. 10

Defense Mechanisms

p. 12

Defense Hierarchy and Links with Psychopathology

p. 13

Longitudinal Changes in Defense Mechanisms

p. 14

OBJECTIVES

p. 16

HYPOTHESES

p. 16

METHODS:

Subjects

p. 17

Treatment

p. 18

Measures

p. 18

Procedure

p. 20

Statistical analysis

p. 21

RESULTS

p. 22

DISCUSSION

p. 24

LIMITATIONS

p. 28

CONCLUSION

p. 28 


\section{LIST OF TABLES}

TABLE 1: Inter-rater reliability for the defensive levels $(n=18)$

p. 42

TABLE 2: Number of subjects improved at the end of treatment.

p. 43

TABLE 3: Early versus late percentage in defensive levels, during psychoanalysis.

p. 44

TABLE 4: Unpaired t-tests of early versus late in Overall Defensive

Functioning, summary defensive levels, and general functioning, during psychoanalysis.

p. 45

TABLE 5: Pre-post effect sizes (ES) for Overall Defensive Functioning, immature defenses, high-adaptive defenses, and general functioning.

\section{APPENDIX}

APPENDIX 1: Hierarchical list of defense mechanisms

p. 47

APPENDIX 2: $\quad$ Ethics certificate

p. 49 


\begin{abstract}
Objective: The aim of this naturalistic study is to examine whether a sample of subjects showed improvements in their defensive functioning after undergoing psychoanalysis.
\end{abstract}

Methods: Seventeen subjects from the Penn Psychoanalytic Treatment Collection with completed, tape-recorded psychoanalyses had their defense mechanisms rated both for early and late sessions.

Results: The pre-post effect size for the change in overall defensive functioning (ODF) of the sample was large (0.76) and statistically significant. The percentage of subjects who improved $(71 \%)$ in their ODF was similar to that found by others who studied the same sample using general functioning measures.

Conclusions: These findings provide the first empirical evidence to support a sustained trait-like change in dynamic personality functioning in patients who have undergone psychoanalysis. Future randomized and controlled studies with homogeneous samples are needed to further confirm these findings. 


\section{RÉSUMÉ}

But : L'objectif de cette étude naturaliste consiste à examiner l'amélioration du fonctionnement défensif auprès d'un échantillon de sujets ayant suivi une psychanalyse.

Méthodologie : À partir de séances pré-enregistrées, les mécanismes de défense de dix-sept (17) sujets ayant complété leurs analyses et recueillis auprès du «Penn Psychoanalytic Treatment Collection» ont été cotés en début et en fin de traitement.

Résultats : La variation de changement pré-post («effect size») dans le fonctionnement défensif global (ODF) de l'échantillon était importante $(0.76)$ et statistiquement significative. Le pourcentage de sujets qui se sont améliorés (71\%) au niveau de leur ODF était comparable au changement rapporté par d'autres chercheurs ayant étudié cet échantillon à partir de mesures de fonctionnement général.

Conclusion : Ces résultats fournissent une première preuve empirique à l'appui d'un changement de fond (au niveau des traits) dans le fonctionnement dynamique de la personnalité chez des sujets qui ont suivi une psychanalyse. Des études subséquentes randomisées et contrôlées auprès d'échantillons homogènes permettront à l'avenir de confirmer ces résultats. 


\section{INTRODUCTION \& REVIEW OF THE LITERATURE}

For years, psychoanalysts have reported observing significant improvements in the adaptive capacities of their patients during the course of psychoanalysis. Reviews of studies in the literature support the clinical impression that patients benefit from psychoanalysis (Bachrach et al 1991; Doidge 1997; Fonagy 1999; Kantrowitz 1997). However, compared to shorterduration therapies, such as cognitive-behavioral therapy, systematic outcome research in psychoanalysis has lagged behind. According to Sandell et al. (2000), up until 2000, the Menninger Project was the only published study that examined individual psychoanalytically oriented therapies with non-psychotic patients of at least 2 years duration, and with at least 2 years follow-up. The results were favorable, and showed that about $60 \%$ of subjects in psychoanalysis or psychotherapy improved.

Other American Psychoanalytic Centers have reported similar improvements at termination. A retrospective study from Boston (Sashin et al, 1975) mailed out questionnaires to analysts, who reported on 130 out of 183 (72\%) selected patients, who had received an average of 675.4 hours of analysis. The results found that a total of $90(69.2 \%)$ treatments had terminated upon mutual agreement between the analyst and the patient. This group was found to have improved significantly in most domains (e.g. global improvement, symptom restriction improvement) compared to other patients whose treatments had not ended by mutual agreement. 
A prospective study out of Boston (Kantrowitz et al., 1987) examined 22 patients who were accepted for psychoanalysis. All were college educated, with $3 / 4$ of them with IQ's that ranged from Superior to Very Superior. The average duration of psychoanalysis was 4.5 years. An object-relations assessment that was based on a battery of standardized psychological tests, was carried out at intake and one year after treatment termination. The results found a significant improvement in the level and quality of object relations. Seventy-seven percent $(17 / 22)$ of the subjects underwent semi-structured interviews 5 to 10 years after termination (Kantrowitz et al. 1990). The transcribed interviews were rated for stability of psychological change, and each patient was given a global rating of change. The results found that seven patients $(41 \%)$ had either improved or retained their psychological gains. Six patients $(35 \%)$ had deteriorated, and then subsequently restored their gains with more treatment, and 4 patients $(24 \%)$ had suffered a deterioration in psychological functioning.

Another retrospective study from New York (Erle, 1979) examined 40 patients who had been selected as supervised analytic cases. Most patients (77.5\%) received more than 2 years of treatment. The results found that $60 \%$ of patients had benefited substantially, according to a 4-point Likert scale that was completed by the analysts at the end of treatment.

A retrospective study from the Center for Psychoanalytic Training and Research of Columbia University (Weber et al, 1985) examined 581 patients who were selected for psychoanalysis or psychotherapy. The durations of their treatments varied considerably. Using the data from the records of the initial 
assessments, the progress reports, and the termination assessments, the raters assessed the therapeutic benefit. Results using an Overall Improvement scale showed that a range of $56 \%$ to $91 \%$ of patients in psychoanalysis had improved or much improved. Within the group of patients who received psychotherapy, $48 \%$ to $61 \%$ improved.

A number of studies out of Germany suggest that psychoanalytic psychotherapy is associated with decreased health-care utilization. Dossman et al. (1997) sent a questionnaire to a sub-sample (20\%) of psychoanalysts in Germany, requesting that they send a copy to patients who had finished their therapy between January 1990 and December 1994. A total of ninety-one therapists participated, and $65 \%$ of their former patients (666/979) returned the questionnaires. The average time since treatment termination was 2 years, 3 months. The results showed patients reported significant improvements in physical health status, psychic health status, quality of social relationships at the end of therapy and at follow-up. They reported using significantly fewer medications for acute illnesses, and fewer psychotropic medications at the end of therapy and at follow-up. Furthermore, they reported making significantly fewer visits to general practitioners and specialists, and having fewer sick days both at the end of therapy and at follow-up. Individual therapy and particularly group therapy were both found to be cost-effective.

A German study (Rudolf, 1991), examined the course 343 patients in psychoanalysis or psychotherapy during 1984 and 1986. Most of the instruments used were designed specifically for the study, and positive outcome was 
calculated using a criterion definition that emphasized mostly a differentiated description of the quality of personality changes. Rates of positive outcome ranged between 50 and $80 \%$, depending on the definition.

Of note, a randomized controlled study of 38 subjects with borderline personality disorder (Bateman et al. 1999) showed that 18 months of treatment consisting of once-weekly psychoanalytic psychotherapy and thrice-weekly group psychoanalytic psychotherapy resulted in significantly more improvement in a number of domains. Specifically, intent-to-treat results showed that more patients from the experimental group compared to the control group refrained from self-mutilation $(p<0.005)$ and suicide attempts $(p<0.004)$ after treatment. These results were maintained during the 18-month follow-up, for both selfmutilation $(p<0.001)$ and suicide attempts $p<0.001)$. Compared to the controls, patients in the experimental group reported lower trait anxiety scores throughout the follow-up period $(p<0.001)$, and also reported that they were less depressed $(p<0.001)$. Treatment was also observed to influence service utilization during the follow-up period. At the 36-month follow-up, patients in the experimental group had required fewer inpatient treatment days compared to the controls $(p<0.001)$, fewer outpatient psychiatric consultations $(p<0.001)$. In addition, fewer of them required medications, compared to controls $(36.4 \%$ vs. $79.0 \%$; $p<0.007)$.

\section{Recent Research in Psychoanalysis and Psychoanalytic Psychotherapy}


Although there has been some recent progress in the area of psychoanalytic research, the field remains challenging for a number of reasons. Psychoanalysis is an intensive, 3 to 5 times per week, treatment that may last up to 6 years or more. For this reason, the practical, ethical, financial and methodological limitations associated with studies of shorter duration, are further intensified with long-term treatment studies (Sandell, Blomberg, \& Lazar, 1997).

Despite the challenges, more recent advancements in the field of psychoanalytic research have ensued. A large naturalistic study by Sandell et al (2000) followed for 3 years, 756 patients in various phases of subsidized psychoanalysis or long-term psychodynamic psychotherapy. Self-report questionnaires were mailed out, and complete data was obtained for 450 subjects in the sample (60\%). The pre-post effect sizes (ES) for a symptom measure (Symptom CheckList-90) were 1.55 and 0.60 , for psychoanalysis and psychotherapy, respectively. For a functioning measure (Social Adjustment Scale) they were $0.45 \& 0.44$, respectively, and for a measure of moral and vitality (Sense of Coherence Scale), they were 1.18 and 0.34 , respectively. Furthermore, by comparing the subject's scale scores to a normal population, they found that the percentage of non-clinical cases before treatment $(12 \%)$ increased to over $70 \%$ in the psychoanalysis group. In the psychotherapy group, the percentage of non-clinical cases increased from $33 \%$ to $55 \%$.

Another study by Freedman et al. (1999) consisted of contacting a group of past or current patients in psychoanalytic psychotherapy by mail. Of the initial 240 patients receiving subsidized or free treatment, $99(41 \%)$ completed a 
revised version of the self-report Effectiveness Questionnaire. Items of the EQ were then extracted and combined to create outcome variables. The Effectiveness Score is composed of three areas: the helpfulness of the therapy, the patient satisfaction with the treatment, and the subjective change in the emotional state after therapy compared to before the therapy. The Adaptive Life Gains measure is based on the patient's ratings of: ability to relate to others, being productive at work, coping with everyday stress, etc. Patients were seen 1 to 3 times per week, and treatment duration ranged from one month to 2 years. The results found a correlation of $0.28(p<0.005)$ between the Effectiveness Scores and the duration of therapy that ranged between 1 and 32 months, indicating that the patients with longer therapies were reporting more effectiveness. For patients with a meaningful treatment exposure (e.g. at least 7 months of therapy), the mean Effectiveness Scores were significantly larger the twice and thrice weekly treatment groups compared to the once weekly group $(F=5.10 ; p<0.01)$. Furthermore, the patient's experience of a positive relationship with the analyst was significantly correlated with the effectiveness score $(r=0.56$; $p<0.001)$

Using the sample of 17 subjects from the Penn Psychoanalytic Treatment Collection, with completed tape-recorded psychoanalyses (the same sample used in the present study), Luborsky et al. (2001) found that $65 \%(11 / 17)$ of subjects showed some or much improvement at termination, according to the Success, Satisfaction, and Improvement (SSI) scale. This figure is similar to that obtained in the Menninger Foundation Psychotherapy Research Project. Using 
the Health Sickness Rating Scale (HSRS), Luborsky et al. (2001) also found a significant positive correlation between the HSRS-early and the HSRS-late $(r=0.62, p<0.01)$. The authors report that this result supports the hypothesis that, the better the early level of functioning, the better the outcome.

As reviewed by Sandell (2001), recent German studies continue to support the hypothesis that psychoanalysis or psychoanalytic psychotherapy decrease health-care consumption and improve the psychological status of patients (Heinzel 2001, Keller et al. 2001; Leuzinger-Bohleber et al 2001; Ruger 2001; Stuhr 2001).

Finally, a feasibility study by Vaughan et al. (2000) found that, despite a small sample size $(n=24)$, a number of significant positive changes were demonstrated after only one year of psychoanalysis or psychoanalytic psychotherapy. Statistically significant improvements were reported for symptom measures, including the Beck Depression Inventory $(p<0.01)$, and the Spielberger State-Trait Anxiety Inventory $(p<0.007)$. Patients also reported an improvement in their interpersonal problems, as per the Inventory of Interpersonal Problems $(p<0.01)$. Additional important findings included lower recruitment rates for psychoanalysis $(27 \%)$ compared to psychoanalytic psychotherapy (83\%). One possible explanation for this is that the cliniciananalysts may have presented the project in a style likely to bring about a refusal. Such an occurrence would indeed illustrate the constraints on empirical research that are imposed by the strong resistance among the psychoanalytic profession to promote and support it. An important task of psychoanalytic researchers will 
be to improve the prevailing negative attitudes about research (Kernberg, 2002). Clearly, future studies will need to recruit psychoanalysts who value empirical research and perceive it as an opportunity to further advance the field.

\section{Defense Mechanisms}

The importance of having well-designed studies in psychoanalysis and psychoanalytic treatments that relate outcome to process is well described in the literature (Gabbard et al. 2002; Kernberg 2002; Wallerstein 2002; Auchincloss 2002). In order to support the hypothesis that psychoanalysis produces sustained, and adaptive changes in personality that are protective against future adversity, researchers will have to include dynamic outcome measures, such as defense mechanisms, that can reflect a shift in personality structure (Wallerstein 2002).

The fourth edition of the Diagnostic and Statistical Manual (1994) states that "Defense mechanisms (or coping styles) are automatic psychological processes that protect the individual against anxiety and from the awareness of internal or external dangers or stressors. Individuals are often unaware of these processes as they operate. (They) mediate the individual's reaction to emotional conflicts and to internal and external stressors." Defense mechanisms are wellknown fundamental concepts in the psychoanalytic and psychodynamic literature. Freud (1964) first introduced the use defenses, such as projection. Since then, others have described various other defenses (Freud 1937; Fenichel 
1945; Symonds 1945; Bibring 1961; Semrad 1967; Kernberg 1967; Kolb 1968; Vaillant 1971; Vaillant 1977; Meissner 1980; Perry 1990; DSM-IV 1994).

\section{Defense Hierarchy and Links with Psychopathology}

A number of empirical studies support the notion that defenses can be hierarchically organized. Some authors have reported that mature defensive functioning is associated with various psychological, and social parameters, including a more adaptive adult Eriksonian life stage (Vaillant \& Milofsky 1980; Vaillant \& Drake 1985), psychosocial adjustment (Vaillant 1976; Vaillant \& Drake 1985; Vaillant and Vaillant 1990; Soldz \& Vaillant 1998), psychological health (Vaillant 1975; Vaillant \& Drake 1985; Soldz \& Vaillant 1998), physical health (Vaillant 1976), higher stages of moral judgment (Hart \& Chmiel, 1992). Perry (2001) found that, patients with higher defensive functioning were more likely to undergo twice-weekly sessions and stay in therapy at 1 year (Perry, 2001). In addition, Ellsworth et al. (1986) found that, among a group of highly obese subjects, those with sustained weight loss had better ratings for defensive maturity. Another study (Vaillant 1985) found a correlation between upward social mobility and four intermediate or mature defense mechanisms, including intellectuallization, dissociation, sublimation, and anticipation. Conversely, the use of predominantly lower-level defenses was associated with more psychopathology. In a sample of subjects with personality and mood disorders, lower level defenses were associated with more symptoms and poorer social role functioning (Perry \& Cooper, 1989; Perry, 1995, 1996), and a worse outcome 
after 6 months among those presenting with a major depression (Hoglend \& Perry, 1998). Chronic depression (Perry \& Cooper, 1986), and dysthymia (Bloch et al. 1993) have also been correlated with the use of lower-level defenses.

Borderline psychopathology was correlated with the use of major image distorting defenses and action defenses, while antisocial psychopathology was associated with minor image-distorting defenses (Perry \& Cooper, 1986). One study by Cramer (1997) found a positive relationship between a state of identity diffusion in young adults and immature defense mechanisms (projection and denial). Conversely, there was no such relationship between achieved identity and the above-mentioned defense mechanisms.

\section{Longitudinal Changes in Defense Mechanisms}

A few studies have examined longitudinal changes in defensive functioning. There is some evidence that defensive functioning may progressively mature naturalistically over the years (Vaillant 1977), and also when patients receive treatment for acute and severe psychiatric illnesses. Ablon (1974) found that two thirds of 36 subjects with primary affective illnesses, who were hospitalized for a mean of 4 months and treated with medications and psychotherapy, demonstrated a decrease in immature defenses, and an increase in more mature defenses. Using the Defense Mechanism Rating Scale in a sample of subjects with personality and mood disorders, Perry (1990) found that the use of immature defenses usually predicted a more severely symptomatic course of illness, while the use of mature defenses was later associated with a 
less severe course. A study by Cramer \& Blatt (1990) reported an overall decrease in the use of lower-level defense mechanisms (denial, projection and identification) in a group of 90 seriously disturbed young adults who received 15 months of intensive in-patient treatment in a psychoanalytically oriented treatment facility. Approximately $30 \%$ of the subjects in this sample were psychotic, $10 \%$ were depressed or severely neurotic, and $60 \%$ had personality disorders. Akkerman et al (1992) reported significant improvement on the Hamilton Depression Rating Scale, the SCL-90-R, and the use of fewer immature defenses at 7 to 9 weeks follow-up among a sample of 37 depressed in-patient subjects. Another study with 28 out-patient subjects (Winston et al. 1994) with predominantly dysthymia (21.4\%), V-codes $(14.3 \%)$ and cluster $C$ personality disorders found that 40 weeks of brief-dynamic psychotherapy, consisting of either short-term dynamic therapy (STPD) or brief adaptive psychotherapy (BAP) resulted in a decrease in intermediate defense mechanisms for BAP only. This sample of 28 subjects did improve significantly at termination on other measures, including the Target Complaints, SCL-90-R, and the Social Adjustment ScaleSR. It is possible that longer treatment durations are required to demonstrate significant and sustained, trait-like improvements in defensive functioning of dysthymic subjects, and that the defensive changes reported in the Ablon and Akkerman studies reflect state-like changes that are related to the remission of acute affective episodes. Due to its longer treatment duration, the study by Cramer \& Blatt may reflect defense changes that occurred both at the state-level and the trait-level. 
Studies have reported on the interrater reliability of the ODF: intraclass $R$ $=0.61$ and 0.89 (Perry \& Cooper, 1989; Perry et al., 1993; Perry \& Hoglend, 1998). In a multisite field trial, with $50 \%$ of subjects diagnosed with major depression, Perry \& Hoglend (1998) found evidence for convergent and discrimant validity for the DMRS. The DMRS-ODF correlated negatively with the presence of a personality disorder, it correlated positively with symptoms (as per the Global Severity Index), it correlated moderately with the self-report ODFscores, obtained using the Defense Style Questionnaire (Bond et al. 1983), and it correlated highly with global functioning scores (as per the GAF). Using both principal components and confirmatory factor analysis, defensive and global functioning were shown to be discriminable.

In contrast, the process by which defense mechanisms actually change in psychoanalysis has yet to be studied systematically.

\section{OBJECTIVES}

The goal of this study is to demonstrate the changes in defensive functioning that occurred in 17 subjects from the Penn Psychoanalytic Treatment Collection who completed a course of psychoanalysis, and to compare these changes with other measures of general functioning.

\section{HYPOTHESES}

Our hypotheses were that, upon completion of their psychoanalysis, the subjects would show: 
1.) an increase in the use of mature defenses, and

2.) a decrease in the use of immature defenses.

\section{METHODS}

\section{SUBJECTS}

This report is only the second one to have used the data-base known as the Penn Psychoanalytic Treatment Collection. Subsequent to the plans delineated during the weekly meetings of the Analytic Research Group (ARG) of the Institute of the Pennsylvania Hospital held between 1972-1976, the Penn Psychoanalytic Collection was gathered. Each of the eight original analyst-members of the ARG designated a priori at least one of their patients as a research case, and thereafter audio-taped all the sessions from the beginning of treatment to the end of treatment. Other subjects originating from different centers were subsequently added to this collection, and the last of the completed psychoanalyses were collected during the mid-1990's. Only 17 cases from the original set of 26 research cases satisfied the inclusion criteria, which were: 1.) the patients were designated as "research cases" prior to the start of treatment; and 2.) all the sessions were audio-taped. The final sample included $11(65 \%)$ females and $6(35 \%)$ males. The estimated mean age of the subjects was $33.6 \pm$ 6.7 years old, and 8 of them (47\%) were married. Aside from the audio-taped psychoanalytic sessions, no other intake or follow-up data was collected on this sample. 


\section{TREATMENT}

The analysts who provided the treatment in this study had practiced psychoanalysis for at least 8 years. The duration of the psychoanalyses ranged between 141 and 1162 sessions (at the 90\%-point of completion), and the subjects were usually seen 4 times per week.

\section{MEASURES}

1.) The Defense Mechanism Rating Scale (DMRS; Perry 1990) measures the use of defense mechanisms from transcribed clinical interviews. It includes 27 defense mechanisms that are categorized into seven hierarchical defensive levels, which are based on similar functional properties and empirical relationships (Perry \& lanni, 1998). The lower defensive levels, 1 through 4 , are considered immature (e.g. the least adaptive), levels 5 and 6 include neurotic defenses, and level 7 include mature defenses (A hierarchical list of the defenses is shown in Appendix 1). The DMRS manual provides a formal definition of each defense, an explanation of its intrapsychic function, and a discussion to discriminate it from other near-neighbor defenses (Perry \& lanni, 1998). Numerous clinically-relevant examples are given for each defense mechanism to help the rater determine its absence or presence. While reading the transcribed interview and listening to the accompanying audiocassette, the rater identifies and labels each defense mechanism as it is encountered in the text. The final score is 
summarized using the Overall Defensive Functioning Score (ODF). This is calculated by multiplying each defense by its weight (e.g. 1 to 7 ) according to its ranking in the hierarchy of defensive levels. The weighted average of all the defenses is then calculated. The resulting ODF score has a theoretical range of 1 to 7 , but clinical samples usually yield scores between 2.5 and 6.0 (Perry \& lanni, 1998). The DMRS has demonstrated fair to good intraclass $R$ inter-rater reliabilities on clinical sessions for the 7 defense levels (range .52 to .89) (Perry \& Cooper, 1989; Perry et al., 1993; Perry \& Hoglend, 1998; Perry, 2001), and for ODF and the number of defenses used per session (.85 and .83, respectively) (Perry, 2001; Despland et al., 2001). In a multisite field trial, with $50 \%$ of subjects diagnosed with major depression, Perry \& Hoglend (1998) found evidence for convergent and discrimant validity for the DMRS. The DMRS-ODF correlated negatively with the presence of a personality disorder, it correlated negatively with symptoms (as per the Global Severity Index), it correlated moderately with the self-report ODF-scores (obtained using the Defense Style Questionnaire; Bond et al. 1983), and it correlated highly with global functioning scores (as per the GAF). Using both principal components and confirmatory factor analysis, defensive and global functioning were shown to be discriminable.

3.) The Psychological Health-Sickness Rating Scale (HSRS; Luborsky 1962) is a global measure of mental health and general functioning 
that yields scores from 0 (total institutional dependency) to 100 (exhibition of multiple measures of positive mental health). HSRS ratings on this sample were previously completed by two independent judges (Luborsky et al., 2001). The mean Spearman correlations of the inter-rater reliabilities were: Rs-early sessions $=0.17$ (n.s.); -late sessions $=0.54(p=0.03)$.

4.) The Global Assessment of Functioning (GAF) Scale is used for assessing the overall mental health and general functioning of a subject. Its score varies from 1 to 100 , with the higher score corresponding to the hypothetically healthiest individual (Endicott et al. 1976). GAF ratings of the sample were also previously collected by two different judges (Luborsky et al., 2001), and the inter-rater reliabilities were: Rs-early sessions $=0.30$ (n.s.); - late sessions $=0.51$ $(p=0.04)$.

5.) Combination of "success", "satisfaction", and "improvement" (SSI) (Luborsky, 1975). Because these scales are designed to measure improvement, they were rated using the three late sessions (at the $90 \%$ point-of-completion). The three facets $(S, S, I)$ tend to overlap, and they were combined into an average rating. An overall score of 6 or greater is consistent with "some improvement", and a score of 7 or greater is consistent with "much improvement". The SSI ratings were also previously collected by two independent judges (Luborsky, 2001). 
The mean Spearman correlation for the inter-rater reliability was 0.74 $(P<0.00)$.

As noted above, the general functioning measures (HSRS, GAF) and the SSI were previously rated on the 17 subjects. However, fewer sessions were used for those ratings $(\mathrm{N}=89)$, compared to the number of sessions used for the defense mechanism ratings of the current study $(\mathrm{N}=149)$.

\section{PROCEDURE}

Each subject had 8 to 10 psychoanalytic sessions transcribed from the audiocassettes, for a total of 149 transcribed sessions. These included 4-to-5 early sessions at or prior to the $10 \%$ point-of-completion, and $4-$ to- 5 late sessions at or after the $90 \%$ point-of-completion of the psychoanalysis. (Due to missing sessions, which could not be located, one subject had only 2 early and 3 late sessions, and another subject had only 3 early and 3 late sessions). For each subject, the transcribed sessions were randomly ordered, blinded as to session number, and labeled using letters "A", "B", ... up to "J", by a research assistant. The three blind raters were psychiatrists from Montreal (C.R., E.B., C.P.) with at least 5 years experience in the quantitative rating of defenses according to the Defense Mechanism Rating Scale (DMRS). Eighty-four transcribed sessions (44\%) had an accompanying audiocassette that was available to the raters for the rating of defenses. After having independently scored the randomized "A" transcript of a subject, two raters met and obtained a consensus rating. After achieving an inter-rater reliability (intraclass $\mathrm{R}$ ) of 0.75 or greater, the main rater 
(C.R.) then scored the remaining sessions "B", "C" etc for that subject. We examined changes in individual defenses, defense levels, and Overall Defensive Functioning (ODF) from early to late sessions.

\section{STATISTICAL ANALYSIS}

Using SAS version 8.2, pre-post within-condition effect sizes (ES) were calculated for overall defensive functioning (ODF), the defensive levels, HSRS and GAF. The ESs were calculated by subtracting the late-sessions' mean from the early-sessions' mean, and dividing by the standard deviation of the mean of the early sessions. Effect sizes reflecting improvement are presented as a positive number. This method of effect size calculation has been used by others (6). Simple linear regressions were used to assess how dependent variables, such as ODF, vary according to session number. Early-late differences in the variables were compared using paired student T-tests. Pearson's correlations were used to examine the relationships between the changes in defense levels during psychoanalysis. Spearman's correlations were used to examine the association between defensive functioning and global functioning.

\section{RESULTS}

The mean session number at the $90 \%$-point of completion of the psychoanalyses was $623 \pm 299$ (median $=516)$, with a range of 141 to 1162 sessions. Assuming 4-sessions per week of psychoanalysis, this would imply a duration ranging from 8 months to 6 years (median $=3$ years). The scoring of 
the early transcripts was done at mean session number $46 \pm 15$ (median 51 ), and that of the late transcripts was done at session number $623 \pm 299$ (median $=516)$.

As shown in Table 1, the raters achieved good inter-rater reliabilities for those defense levels with sufficient base rates (intraclass $R=0.49$ to 0.88 ). The mean intra-class correlation for the Overall Defensive Functioning (ODF) was 0.83 .

The linear regression results of the ODF and other defensive levels as a function of session number are shown in Table 2. Out of 17 subjects, $12(71 \%)$ demonstrated an improvement in their ODF, $10(59 \%)$ used fewer immature defenses, $12(71 \%)$ used fewer action level defenses, and $13(76 \%)$ used more mature defenses. T-tests for change in ODF were also calculated, and the results for individual subjects were the same compared to the linear regressions. The sign test for the average change in ODF of the sample was not significant $(p=0.14)$, however, the signed rank test was significant $(p=0.03)$. As per Luborsky et al, (2001), a similar percentage of subjects showed similar overall improvements in their general functioning according to the Health Sickness Rating Scale ( $76 \%$ of subjects improved), the Global Assessment of Functioning ( $76 \%$ of subjects improved), and the SSI (65\% of subjects improved). The percentages of subjects with statistically significant improvements were smaller, in particular for the defensive functioning variables.

As hypothesized, Table 3 shows that the percentage of high adaptive defenses rated increased from an initial $2.22 \%$ to $5.21 \%$ at the end of treatment $(p=0.0007)$, and the percentage use of action defenses dropped from $3.24 \%$ 
down to $1.92 \%(p=0.07)$. The use of major-image distorting and disavowal defensive levels decreased as expected, but these changes were not statistically significant. There was no notable change in the other defensive levels (minor image-distorting, displacement/reaction formation, hysterical, and obsessional). As shown in Table 4, the sample showed a statistically significant change in the mean ODF, which increased from $4.95 \pm 0.21$ for the early sessions to $5.10 \pm 0.24$ at the end of treatment $(p=0.01)$. This was consistent with an increase in the use of high adaptive defenses, and a drop in immature defenses. No overall change was seen in the neurotic level defenses. A significant increase in general functioning was observed, according to the HSRS and the GAF (Luborsky et al, 2001). As shown in Table 5, the pre-post within condition effect size (ES) for ODF was large and significant $(E S=0.76 \pm 1.09, p=0.01)$. At the end of the analyses, subjects used fewer immature defenses, as shown by a moderate trend in the effect size $(E S=-0.44 \pm 0.93, p=0.07)$ and a greater proportion of mature defenses, as shown by a large and statistically significant effect size $(E S=1.49 \pm 1.79, p=0.003)$. General functioning according to the HSRS and the GAF also improved, as shown by large effect sizes, which were statistically significant (Luborsky et al, 2001).

Positive, but non-significant correlations between changes in defensive functioning and global functioning were found, according to the HSRS (Spearman's $r=0.12, n . s$ ) and the GAF (Spearman's $r=0.26$, n.s.). 
Finally, a statistically significant negative correlation was found between the overall change in the immature level defenses and that of the neurotic level defenses (Pearson's $\left.I_{r}=-0.88, p<0.0001\right)$.

\section{DISCUSSION}

Using the Penn Psychoanalytic Treatment Collection to examine changes in defensive functioning has been particularly stimulating for our research group for a number of reasons: 1.) this sample is the first of its kind to provide raw data on completed and fully-audiotaped psychoanalyses to be used in process research; 2.) the sample allowed the first such study of how defenses change in psychoanalysis; 3.) it allowed us to collaborate with another research group that had already used the Penn Collection, and to compare our results with theirs (Luborsky et al., 2001); and finally 4.) future projects using the Penn Collection are in various stages of planning, and will allow further comparisons between studies.

The inter-rater reliability of the Defense Mechanism Rating Scale was generally good, and showed moderate-to-large intraclass correlations, in line with other reports (Perry, 2001; Despland et al., 2001; Perry \& Henry, in press).

Our finding that $71 \%$ of the subjects improved in their defensive functioning converged with the findings of Luborsky et al., (2001) which showed that $76 \%$ of the subjects (in the same sample) had improved in their general functioning according to both the HSRS and the GAF. However, the percentage of subjects who improved statistically significantly, using individual regression 
models for each patient, was relatively lower for both the defenses and general functioning. This is probably due to the small number of sessions for each subject, which usually ranged from 8 to 10 for the defense ratings, and only 4 to 6 for the GAF and HSRS ratings. However, the sign rank test for the change in ODF of the sample was significant. This indicates that the magnitude of positive changes was significantly larger than the magnitude of negative changes.

The two extreme levels of the defensive hierarchy, the high adaptive and the action level defenses were the only ones to show statistically significant changes in the expected directions at the end of treatment. That is, the former were used more frequently, and the latter were used less frequently. In contrast, there was little change in the number of mid-level defenses in the sample at the end of treatment. This study sheds less light on how neurotic defenses improve during the course of psychoanalysis. The magnitude and rate of change that occur may be dependent on a number of factors, including the duration of the psychoanalysis, and the initial diagnosis and personality traits of the individual patient and the prevalence of defense interpretation by the analyst. As previously mentioned, our heterogeneous sample did not undergo independent intake diagnostic assessments, and included treatments of varying lengths. Nevertheless, our results generally support Vaillant's hierarchical hypothesis, that as individuals age from adolescence to mid-adulthood, they gradually trade off their initial immature defenses for more neurotic level defenses, and eventually acquire more mature defenses (Perry, 2001). This is consistent with the statistically significant finding $(p<0.0001)$ that as the use of immature level 
defenses decreased in psychoanalysis, the frequency of neurotic level defenses increased.

The overall improvement in defensive functioning (ODF) at the end of treatment was statistically significant $(p=0.01)$, which was consistent with the statistically significant improvements in general functioning, according to both the HSRS and the GAF. However, the Spearman correlations between changes in defensive functioning and global functioning, according to HSRS and GAF were small and not significant. This is in contrast with other authors (Perry \& Hoglend, 1998), who found evidence for convergent validity in a moderately large and significant correlation between ODF and GAF at intake. There are a number of possible explanations for the small correlations reported in this study. Namely, this study had fewer subjects, and it demonstrated a narrower range of initial defensive functioning and global functioning, as demonstrated by the much smaller standard deviations at intake. Similarly, the narrow range of initial global functioning, according to the HSRS and the GAF, the small sample size, and the lack of data from intake interviews, could also account for the small interrater reliabilities for HSRS and GAF reported by Luborsky et al. (2001).

An improvement in ODF from 4.95 to 5.10 indicates an absolute improvement of 0.15 units on the ODF scale. In a sample of personality $(80 \%)$ and mood (40\%) disorders entering open-ended psychotherapy, Perry (2001) found an improvement in ODF of 0.07 points ( 4.27 to 4.34 ) after 12 months of once or twice weekly dynamic therapy. In a Norwegian sample, $49 \%$ of which presented with a major depressive episode and $62 \%$ with a personality disorder, 
Perry \& Hoglend (1998) found an improvement in ODF after six months of outpatient treatment of 0.43 (4.68 to 5.11). In a second Norwegian sample with $65 \%$ personality disorders, and few major depressions (16\%), Hersoug et al. (2002) found that, after one year of dynamic psychotherapy, ODF improved by 0.42 (4.40 to 4.82). Comparisons with the Penn collection sample are difficult because of the lack of independent diagnostic information. Nonetheless, the Penn Collection sample started at a higher ODF, consistent largely with neurotic character problems rather than specific Axis I or II disorders, which usually present with lower ODF (Perry \& Henry, in press). This suggests the possibility that defensive change occurs more slowly in samples presenting with neurotic character issues compared to those with Axis I and II disorders. Two other possible explanations for the small ODF improvement of this report include: the (atypical) introductory sessions (e.g. session numbers $1 \& 2$ ) that were rated and included in the early-session group. These sessions were relatively more structured since the analyst asked frequent questions, which may have artificially increased the initial defensive functioning by facilitating the use of obsessional defenses by the subjects. The nature of the analysts' interventions will be examined in an upcoming study (Banon et al, unpublished). Second, the initial ODF may have been artificially increased by the "honeymoon effect", which is a common phenomenon that occurs during the first month(s) of therapy. Typically, it produces a rapid, but unsustainable improvement, as the patient's level of emotional distress decreases (e.g. a state effect) as he begins to tell his story (Perry et al., 1999). In a 4-session Brief Dynamic Investigation of individuals 
presenting in a crisis, Drapeau et al. (in press) reported improvement in ODF of 0.28 (4.37 to 4.65 ) which they interpreted as due to state effects, including regression to the mean and the so-called honeymoon effects attendant with relief at discussing one's problems with a knowledgeable professional. Due to the limited number of transcripts available to us, all the early sessions, including the initial introductory ones, had to be included. The archival nature of our sample may also account for a smaller change in ODF, since the prevalence of medication use is not known. However, one can assume that, compared to more recent long-term psychotherapy studies, fewer subjects would have been on medications.

The issue of the clinical significance of a 0.15 improvement in ODF (from 4.95 to 5.10 ) in the sample needs to be addressed. Clearly, this implies that, even though most patients did improve, some of them either got worse or did not change following a considerably lengthy treatment. A final mean ODF of $5.10 \pm 0.24$ indicates that overall, the sample continued to have less-than-optimal defensive functioning. As part of a larger study (Perry et al., personal communication), a control group of healthy community mothers who had been screened for the absence of a history of psychiatric treatment, and who had no current psychiatric complaints demonstrated a mean ODF of $5.67 \pm 0.52$. There are a number of possible explanations for the small overall change in ODF in this study. Psychoanalytic sessions may not be an optimal source from which to measure pre-post changes in defensive functioning. By nature, the psychoanalytic process is an artificial setting that requires the use of free 
association of thoughts, feelings, and impulses. Being that the patient is in treatment to discuss and resolve his problems, he/she may naturally present the material in a biased fashion. That is, the "negatively-toned" stories, affects and events likely associated with lower-level defenses may be presented more frequently than the patient's "success stories" or accomplishments that would be associated with the use of more mature defenses. Also, it may be that psychoanalysts from that generation were overly "neutral", and they may not have focused sufficiently on the use of defense interpretations during their interventions. This may have inadvertently resulted in less improvement in defenses. Furthermore, a better test of defensive change from psychoanalysis would be to do ratings using specific interviews that are specifically designed to elicit patient defenses, and to compare the results at intake, termination, and follow-up. Examples of interviews that could be used for this purpose include: the Relationship Anecdotes Paradigm Interview (RAP; Luborsky, 1990), and the Dynamic Interview (Perry \& Cooper, 1989). Finally, due to the lack of a control group, it cannot be ruled out that the improvement in ODF is due in part to the maturation process, which occurs independently of the analysis.

The large and statistically significant pre-post effect size (ES) for the Overall Defensive Functioning of the sample shows that, on average, the subjects were using more adaptive defenses at the end of their psychoanalyses. Indeed, they were shown to use fewer immature defenses, as shown by a negative ES, and to use High Adaptive defenses more frequently, as shown by a large positive ES. Furthermore, these findings are consistent with an 
improvement in general functioning, as shown by the large pre-post effect sizes for the general functioning measures, HSRS and GAF.

\section{LIMITATIONS}

Despite the importance of this study, which used the first available sample of completed and tape-recorded psychoanalyses, there were a number of limitations. It included only 17 subjects, which limits the power of the study. Because most of the data was gathered more than 20 years ago, it provided only audio-taped sessions. There were no standardized diagnostic or other interviews designed to collect intake and outcome data, and the prevalence of medications used is unknown. It had no control group to demonstrate that the improvements in defensive functioning were due to the psychoanalysis, and not due to the passage of time or chance alone.

Even though the raters of the defense mechanisms were always blind to session number, occasionally, the material brought forward by the patient or the analyst alluded to the timing of the sessions (e.g. whether it was an "early" or "late" session). However, this information was usually unreliable. That is, a session that seemed to occur in the "early" stages, in fact turned out to be a "late" session once the blinding was uncovered, and vice-versa.

Finally, as would be expected with any archival data collected during this period, the sound quality of the audiocassettes was occasionally poor, and not all of the reels had been transferred to more modern audiocassettes, and therefore, the latter were not always available to the raters at our institution. A possible 
disadvantage of rating with transcripts alone (Perry \& Henry, 2003, in press) is that the rater may miss those defenses that are best identified by affective and behavioral cues (e.g. the sarcastic undertones of a devaluation may not be picked up via text alone).

\section{CONCLUSIONS}

In summary, this naturalistic study found that, the subjects demonstrated improvements in their Overall Defensive functioning. At the end of treatment, they were shown to use immature defenses less frequently, and to use mature defenses more frequently. Furthermore, our results are consistent with those of Luborsky et al. (2001), who studied the same sample. They showed a similar percentage of subjects who had improved in their general functioning. However, because the overall improvement in defenses was smaller in magnitude than expected, it will be important for other studies to utilize specific independent interviews for the rating of defenses at intake, termination, and follow-up. The use of psychoanalytic sessions as the sole data source to measure defensive functioning may not be appropriate due to the nature of the process.

Our study is the first to systematically examine the changes in defense mechanisms over the course of psychoanalysis. Our findings should provide clinicians and researchers with a greater understanding about the structural changes that occur during psychoanalysis. Such information can form the basis of future studies that will help delineate those specific interventions that are the most effective. 
The findings of our study are encouraging and will need further replication in a prospective study. It is important that researchers persist in their efforts to further develop the field of psychoanalysis and psychoanalytic psychotherapy research. Long-term studies with sound methodology, including diagnostically homogenous groups of patients, randomized-control groups, and manual-based treatment are still lacking. Experience suggests that studies should include clinician-analysts who have a positive attitude toward research, since this may increase the likelihood of recruiting subjects. Providing empirical evidence to support the well-known clinical experience that "psychoanalysis works" will enhance its recognition among academic institutions, mental health funding agencies, and the population at large. This should in turn provide patients with an effective treatment with which to alleviate their mental suffering and improve their general functioning. 


\section{REFERENCES}

Ablon SL, Carlson GA, Goodwin FK. (1974). Ego defense patterns in manicdepressive illness. American Journal of Psychiatry 131(7):803-807.

Auchincloss EL. (2002). The place of psychoanalytic treatments within psychiatry. Archives of General Psychiatry 59:501-503.

Akkerman K, Carr V, Lewin T. (1992). Changes in ego defenses with recovery from depression. Journal of Nervous and Mental Disease 180:634-638.

American Psychiatric Association: Diagnostic and Statistical Manual of Mental Disorders, Fourth Edition. Washington, DC, American Psychiatric Association, 1994, pp.751-756.

Bachrach HM, Galatzerolevy R, Skonikoff A, Waldron S, Waldron, S. (1991). On the efficacy of psychoanalysis. Journal of the American Psychoanalytic Association, 39:871-916.

Bateman A, Fonagy P. Treatment of borderline personality disorder with psychoanalytically oriented partial hospitalization: An 18 month follow-up. Am J Psychiatry 2001;158:36-42.

Bibring GL, Dwyer TF, Huntington DS, Valenstein A. (1961). A study of the psychological process in pregnancy and of the earliest mother-child relationship: II. Methodological considerations. Psychoanalytic Study of the Child 16:25-72.

Bloch AL, Shear MK, Markowitz JC, Leon AC, Perry JC. L. (1993). An empirical study of defense mechanisms in dysthymia. American Journal of Psychiatry 150:1194-1198. 
Bond M, Gardner ST, Christian J, Sigal JJ. (1983). Empirical study of self-rated defense styles. Archives of General Psychiatry 40:333-338.

Cramer P. (1997). Identity, Personality, and defense mechanisms: An observerbased study. Journal of Research in Personality 31:58-77.

Cramer P, Blatt SJ. (1990). Use of the TAT to measure change in defense mechanisms following intensive psychotherapy. Journal of Personality Assessment 54(1 \& 2):236-251.

Despland JN, Despars J, de Roten Y, Stiglar M, Perry JC. (2001). Contribution of patient defense mechanisms and therapist interventions to the development of early therapeutic alliance in a Brief Psychodynamic Investigation. Journal of Psychotherapy Practice and Research 10 (3):155-164 .

Doidge, N. (1997). Empirical evidence for the efficacy of psychoanalytic psychotherapies and psychoanalysis: An overview. Psychoanalytic Inquiry 17(Supplement):102-150.

Dossman R, Kutter P, Heinzel R, Wurmser L. (1997). The long-term benefits of intensive psychotherapy: A view from Germany. Psychoanal Inquiry 17(Supplement): 74-86.

Drapeau M, de Roten Y, Perry JC \& Despland JN. A study of stability and change in defense mechanisms during a Brief Dynamic Investigation. Journal of Nervous and Mental Diseases (in press, 2003). 
Ellsworth GA, Vaillant GE, Strain GW, Knittle J, Strain GW, Zumoff B. (1986).

Defensive maturity ratings and sustained weight loss in obesity.

Psychosomatics 27(11):772-781.

Endicott J, Spitzer RL, Fleiss JL, Cohen J. (1976). The Global Assessment

Scale. A procedure for measuring overall severity of psychiatric disturbance. Archives of General Psychiatry 33:766-771.

Erle, J. (1979). An approach to the study of analyzability and analysis: the course of forty consecutive cases selected for supervised analysis.

Psychoanalytic Quarterly 48:198-228.

Fenichel, O. (1945). The Psychoanalytical Theory of Neurosis. New York, WW Norton \& Co.

Fonagy, P. (Ed.) (1991). An open door review of outcome studies in psychoanalysis. Report prepared by the Research Committee of the IPA at the request of the President (On-line). Available: www.ipa.org.uk.

Freedman N, Hoffenberg JD, Vorus N, Frosch. (1999). The effectiveness of psychoanalytic psychotherapy: The role of treatment duration, frequency of sessions, and the therapeutic relationship. Journal of the American Psychoanalytic Association 47(3):741-772.

Freud A. (1937). Ego and the Mechanisms of Defense. London: Hogarth press.

Freud S. (1964). The neuro-psychoses of defense (1894). In The Standard Edition of the complete Psychological Works of Sigmund Freud, ed J. Strachey, A. Freud, A. Strachey \& A. Tyson. London: Hogarth Press, vol 3, pp. 41-62. 
Gabbard GO, Gunderson JG, Fonagy P. (2002). The place of psychoanalytic treatments within psychiatry. Archives of General Psychiatry 59:505-510.

Hart D, Chmiel S. (1992). Influence of defense mechanisms on moral judgment development: A longitudinal study. Developmental Psychology 28(4):722-730.

Heinzel R. (2001). Psychotherapie verringert Gusundheitskosten-ambulante analytsche Einzel- und Gruppenpsychotherapie in einer bundesweiten katamnestischen evaluationsstudie. In Langzeitpsychotherapie. Perspektiven fur Therapeuten und Wissenschaftler, ed. U. Stuhr, M. Leuzinger-Bohleber, \& M. Beutel. Stuttgart: Kohlhammer, pp. 356-78. Herzoug AG, Sexton HC, Hoglend PA. (2002). Contribution of defensive functioning to the quality of working alliance and psychotherapy outcome. American Journal of Psychiatry 56:539-554.

Hoglend P, Perry JC. (1998). Defensive functioning predicts improvement in major depressive episodes. The Journal of Nervous and Mental Disease 186(4): 238-243.

Kantrowitz JL. (1997). A brief review of psychoanalytic outcome research. Psychoanalytic Inquiry 87-101.

Kantrowitz JL, Katz AL, Paolitto F. (1990) Followup of psychoanalysis five to ten years after termination: I. Stability of Change. Journal of the American Psychoanalytic Association 38(2):471-496.

Kantrowitz JL, Katz A, Paolitto F, Sashin J, Solomon L. (1987). Changes in level and quality of object relations in psychoanalysis: follow-up of a 
Iongitudinal prospective study. Journal of the American Psychoanalytic Association 35:23-46.

Keller W, Westhoff G, Dilg R, Rohner R, Studt HH. (2001). Wirksamkeit und Kosten-Nutzen-Aspekte ambulanter (jungianischer) Psychoanalysen und Psychotherapien-Eine katamnestische Studie. In Langzeitpsychotherapie. Perspektiven fur Therpeuten und Wissenschaftler, ed. U. Stuhr, M. Leuzinger-Bohleber, M. Beutel M. Stuttgart: Kohlhammer, pp. 343-55. Kernberg OF. (2002). Psychoanalytic contributions to psychiatry. Archives of General Psychiaty 59:497-498.

Kernberg OF. (1967). Borderline personality organization. Journal of the American Psychoanalytic Association 15:641-685.

Kolb LC. (1968). Noyes' Modern Clinical psychiatry. Philadelphia, WB: Sanders Co.

Leuzinger-Bohleber M. (2001). Katamnesen-ihre klinische Relevanz. In Langzeitpsychotherapie, Perspektiven fur therapeuten und wissenschaftler, ed. U. Stuhr, M. Leuzinger-Bohleber, M. Beutel. Stuttgart: Kohlhammer, pp. 160-86.

Luborsky L. (1962). Clinicians' judgments of mental health. Archives of General Psychiatry 7:407-417.

Luborsky L. (1975). Assessment of outcome of psychotherapy by independent clinical evaluators: A review of the most highly recommended research measures. In Psychotherapy Change Measures, ed. I.E. Waskow \& M.B. Parloff. Section on Psychotherapy and Behavioral Intervention, Clinical 
Research Branch NIMH: DHEW Publication No. (ADM) 74-120, pp. 233242.

Luborsky L. (1990). The Relationship Anecdotes Paradigm (RAP) Interview as a versatile source of narratives. In Understanding Transference. The CCRT Method, ed. L.L. Luborsky \& P. Crits-Christoph. Basic Books, Inc., NY Luborsky L, Stuart J, Friedman S, Kiguer L, Seligman DA, Bucci W, Pulver, Krause ED, Ermold J, Davison WT, Woody G, Mergenthaler E. (2001). The Penn psychoanalytic treatment collection: a set of complete and recorded psychoanalyses as a research source. Journal of the American Psychoanalytic Association 49(1):217-234.

Meissner WW. (1980). Theories of personality and psychopathology: Classical psychoanalysis. In Comprehensive Textbook of Psychiatry, ed. H.I. Kaplan, A.H. Freedman,, B.F. Sadock BF. Baltimore Williams \& Wilkins, pp 631-728.

Perry JC. (1990). Defense mechanism rating scales (DMRS), $5^{\text {th }}$ ed., Cambridge, MA.

Perry JC. (1990). Psychological defense mechanisms in the study of affective and anxiety disorders. In Co-morbidity in anxiety and mood disorders, ed. J. Maser \& C.R. Cloninger. Washington, DC: American Psychiatric Press, pp.545-562.

Perry JC. (1995). A pilot study of defenses in long-term dynamic psychotherapy of personality disorders. Paper presented at the $4^{\text {th }}$ international Congress on the disorders of personality, Trinity College, Dublin, Ireland. 
Perry JC. (1996). Defense mechanisms in impulsive versus obsessivecompulsive disorders. In Impulsive Versus Obsessive-Compulsive Disorders, ed. J. Oldham \& A.E. Skodol. Washington, DC: American Psychiatric Press, pp. 195-230.

Perry JC. (2001). A pilot study of defenses in psychotherapy of personality disorders entering psychotherapy. Journal of Nervous and Mental Diseases 189:651-660.

Perry JC, Banon E, lanni F. (1999). Effectiveness of Psychotherapy for Personality Disorders. American Journal of Psychiatry 156:1312-1321. Perry JC \& Cooper SH. (1986). A preliminary report on defenses and conflicts associated with borderline personality disorder. Journal of the American Psychoanalytic Association 34:863-895.

Perry JC \& Cooper SH. (1989). An empirical study of defense mechanisms: 1. Clinical interview and life vignette ratings. Archives of General Psychiatry 46:444-452.

Perry JC, Henry M. (2003). Studying Defense Mechanisms in Psychotherapy Using the Defense Mechanism Rating Scales. In Defense Mechanisms: Theoretical, Research and Clinical Perspectives, ed. U. Hentschel, G. Smith, J. Draguns. Elsevier, Amsterdam (to be published, 2003).

Perry JC, Hoglend P. (1998). Convergent and discriminant validity of Overall Defensive Functioning. Journal of Nervous and Mental Disease 186:529535. 
Perry JC, Hoglend P, Shear K, Vaillant GE, Horowitz MJ, Kardos ME, Bille H, Kagan D. (1998). Field trial of a diagnostic Axis for defense mechanisms for DSM-IV. Journal of Personality Disorders 12:1-13.

Perry JC, lanni, F.F. (1998). Observer-rated measures of defense mechanisms. Journal of Personality Disorder 66(6):993-1023.

Perry JC, Kardos ME, Pagano CJ. (1993). The study of defenses in psychotherapy using the Defense Mechanism Scale (DMRS). In The concept of defense mechanisms in contemporary psychology: Theoretical, research, and clinical perspectives, ed. U. Hentschel \& W. Ehlers. New York, Springer, pp. 122-132.

Rudolf G. (1991). Free University of Berlin: Berlin Psychotherapy Study. In Psychotherapy Research. An international review of programmatic studies, ed. L. Beutler, \& M. Crago. Washington: American Psychological Association, pp. 185-193.

Ruger B. (2001). Statistisches Design und reprasentativitet der psychoanalytischen katamnese-studie (DPV), In Langzeitpsychotherapie. Perspektiven fur Ttherapeuten und Wissenschaftler, ed. U. Stuhr, M. Leuzinger-Bohleber, M. Beutel M. Stuttgart: Kohlhammer, pp. 149-59. Sandell R. (2001). Can psychoanalysis become empirically supported? International Forum of Psychoanalysis 10:184-190.

Sandell R. Blomberg J, Lazar A. (1997). When reality doesn't fit the blueprint: doing research on psychoanalysis and long-term psychotherapy in a public health service program. Psychotherapy Research 7(4):333-344. 
Sandell R. Blomberg J, Lazar A, Carlsson, J, Broberg, J, Schubert, J. (2000). Varieties of long-term outcome among patients in psychoanalysis and long-term psychotherapy. A review of findings in the Stockholm outcome of psychoanalysis and psychotherapy project. (STOPP). International Journal of Psychoanalysis 81:921-942.

Sashin J, Eldred S, Van Amerrowgen ST. (1975). A search for predictive factors in institute supervised cases: a retrospective study of 183 cases from 1959-1966 at the Boston Psychoanalytic Society and Institute. Internation Journal of Psychoanalysis 56:343-59.

Semrad E. (1967). The organization of ego defenses and object loss. In The Loss of Loved Ones, ed. D.M. Moriarity. Springfield, III:Charles C Thomas Publisher.

Soldz A, Vaillant GE. (1998). A 50-year longitudinal study of defense use among inner city men: A validation of the DSM-IV defense axis. Journal of Nervous and Mental Disease 186:104-111.

Stuhr U. (2001). Methodische Uberlegungen zur Kombination qualitativer und quantitativer methoden in der psychoanalytisschen katamneseforschung und hinweise zu ihrer integration. In Langzeitpsychotherapie. Perspektiven fur therpeuten und wissenschaftler, ed. U. Stuhr, M. Leuzinger-Bohleber, M. Beutel. Stuttgart: Kohlhammer, pp. 133-48. Symonds PM. (1945). Defenses: The Dynamics of Human Adjustment. East Norwalk, Conn: Appleton-Century-Crofts. 
Vaillant GE. (1976). Natural history of male psychological health: V. The relation of choice of ego mechanisms of defense to adult adjustment. Archives of General Psychiatry 33:535-545.

Vaillant GE. (1971). Theoretical hierarchy of adaptive ego mechanisms.

Archives of General Psychiatry 24:107-118.

Vaillant GE. (1977). Adaptation to Life. Boston: Little, Brown \& Co.

Vaillant GE, Drake RE. (1985). Maturity of ego defenses in relation to DSM-III axis II personality disorder. Archives of General Psychiatry 42:597-601.

Vaillant GE, Milofsky E. (1980). Natural history of male psychological health: IX. Empirical evidence for Erikson's model of the life cycle. Amercian Journal of Psychiatry 137:11.

Vaillant GE, Vaillant CO. (1990). Natural history of make psychological health, XII: A 45-year study of predictors of successful aging at 65 . American Journal of Psychiatry 147:31-37.

Vaughan SC, Marshall RD, MacKonnon RA, Vaughan R, Mellman L, Rosse SP. (2000). Can we do psychoanalytic outcome research? A feasibility study. International Journal of Psychoanalysis 81:513-527.

Wallerstein RS. (2002). Psychoanalytic treatments within psychiatry. An expanded view. Archives of General Psychiatry 59:499-500.

Weber J, Bachrach H, Solomon M. (1985). Factors associated with the outcome of psychoanalysis: Report of the Colombia Psychoanalytic Center Research Project (II). International Review of Psychoanalysis 12:127-41. 
Winston B, Winston A, Samstag LW, Muran JC. (1994). Patient defense/therapist interventions. Psychotherapy 31(3):478-491. 
Table 1. Inter-rater reliability for the defensive levels $(n=18)$.

\begin{tabular}{l|c|c|c}
\hline Defensive Level & $\begin{array}{c}\text { Intraclass } \\
\text { Correlation }\end{array}$ & \multicolumn{2}{|c}{ \% Base Rate } \\
& $\left(I_{R}\right)$ & Rater 1 & Rater 2 or 3 \\
\hline Mature & 0.77 & 3.0 & 5.2 \\
Obsessional & 0.82 & 37.2 & 37.4 \\
Hysterical & 0.59 & 18.0 & 15.8 \\
Displacement & 0.77 & 19.2 & 17.6 \\
ReactionFormation & & & \\
Narcissistic & 0.65 & 13.6 & 14.7 \\
Disavowal & 0.49 & 4.9 & 6.2 \\
Borderline* & 0.07 & 0.29 & 0.24 \\
Action & 0.88 & 2.8 & 2.6 \\
& & &
\end{tabular}

*very low base rate 
Table 2. Number of subjects improved at the end of treatment.

\begin{tabular}{|c|c|c|}
\hline & $\begin{array}{c}\text { Improved ( } \mathbf{n = 1 7 )} \\
\text { (n) }(\%)\end{array}$ & $\begin{array}{c}\text { Significantly } \\
\text { Improved }(n=17) \\
(n)(\%)^{\star}\end{array}$ \\
\hline ODF & $12(71)$ & $4(24)$ \\
\hline Immature levels & $10(59)$ & $3(18)$ \\
\hline Action levels & $12(71)$ & $2(12)$ \\
\hline Mature levels & $13(76)$ & $1(6)$ \\
\hline HSRS & $13(76)$ & $9(53)$ \\
\hline GAF & $13(76)$ & $7(41)$ \\
\hline SSI & $11(65)$ & -- \\
\hline
\end{tabular}

*Significance $(p \leq 0.05)$ based on individual patient simple linear regression models. Key: ODF $=$ Overall Defensive Functioning; HSRS $=$ Health Sickness Rating Scale; GAF = Global Assessment of Functioning; $\mathrm{SSI}=$ Combination of "Success", "Satisfaction", and "Improvement". 
Table 3. Early versus late percentage in defensive levels, during psychoanalysis $(n=17)$.

\begin{tabular}{|c|c|c|c|}
\hline Variable & Early mean+SD & Late mean $\pm S D$ & P-value \\
\hline \%High Adaptive* & $2.22 \pm 1.95$ & $5.21 \pm 3.99$ & 0.0007 \\
\hline \%Obsessional & $36.54 \pm 6.14$ & $36.37 \pm 9.07$ & n.s. \\
\hline \%Hysterical & $18.28 \pm 4.95$ & $19.26 \pm 4.78$ & n.s. \\
\hline \%Displacement/R.F. & $16.20 \pm 3.38$ & $15.97 \pm 4.49$ & n.s. \\
\hline $\begin{array}{l}\text { \%Minor image- } \\
\text { distorting }\end{array}$ & $14.23 \pm 5.85$ & $13.65 \pm 6.68$ & n.s. \\
\hline \%Disavowal & $8.89 \pm 3.17$ & $7.42 \pm 4.27$ & n.s. \\
\hline $\begin{array}{l}\text { \%Major image- } \\
\text { distorting }\end{array}$ & $0.34 \pm 0.50$ & $0.20 \pm 0.38$ & n.s. \\
\hline \%Action & $3.24 \pm 3.08$ & $1.92+1.65$ & 0.07 \\
\hline
\end{tabular}

Key: R.F. $=$ Reaction Formation

${ }^{*} \mathrm{p}$-value as per the sign rank test. 
Table 4. Unpaired t-tests of early versus late in Overall Defensive Functioning, summary defensive levels, and general functioning, during psychoanalysis $(n=17)$.

\begin{tabular}{|c|c|c|c|}
\hline Variable & Early mean $\pm S D$ & Late mean $\pm S D$ & P-value \\
\hline ODF & $4.95 \pm 0.21$ & $5.10 \pm 0.24$ & 0.01 \\
\hline \%high adaptive* & $2.22 \pm 1.95$ & $5.21 \pm 3.99$ & 0.0007 \\
\hline$\%$ neurotic & $71.03 \pm 8.10$ & $71.60 \pm 7.91$ & n.s. \\
\hline \%immature & $26.75 \pm 7.94$ & $23.20 \pm 8.19$ & 0.07 \\
\hline HSRS & $59.08 \pm 4.63$ & $63.25 \pm 5.62$ & 0.002 \\
\hline GAF & $58.27 \pm 4.29$ & $62.85+4.55$ & 0.003 \\
\hline
\end{tabular}

Key: ODF $=$ Overall Defensive Functioning; HSRS $=$ Health Sickness Rating Scale $; \mathrm{GAF}=$ Global Assessment of Functioning

${ }^{*} \mathrm{p}$-value as per the sign rank test. 
Table 5. Pre-post effect Sizes (ES) for Overall Defensive Functioning, immature defenses, mature defenses, and general functioning.

\begin{tabular}{l|cc|} 
Dependent Variable & $\begin{array}{c}\text { Effect Size } \\
(\mathbf{n}=\mathbf{1 7})\end{array}$ & $\mathbf{p}$-value \\
\hline ODF & $0.76 \pm 1.09$ & 0.01 \\
$\%$ Immature defenses & $-0.44 \pm 0.93$ & 0.07 \\
$\%$ Mature defenses & $1.49 \pm 1.79$ & 0.003 \\
\hline HSRS & $0.90 \pm 0.98$ & 0.002 \\
GAF & $1.07 \pm 1.23$ & 0.003
\end{tabular}

Key: $\mathrm{ODF}=$ Overall Defensive Functioning; HSRS $=$ Health Sickness Rating Scale $; \mathrm{GAF}=$ Global Assessment of Functioning .

* The weighted ES, according to time, and gave those subjects with a larger number of sessions more weight. 
APPENDIX I. Hierarchical list of defense mechanisms in the Defense

Mechanism Rating Scale (DMRS)

HIGH ADAPTIVE LEVEL

Affiliation

Altruism

Anticipation

Humor

Self-assertion

Self-observation

Sublimation

Suppression

OBSESSIONAL

Isolation

Intellectualization

Undoing

OTHER NEUROTIC

Repression

Dissociation

Reaction formation

Displacement

MINOR IMAGE-DISTORTING (Narcissistic)

Omnipotent 
Idealization

Devaluation of self

Devaluation of others

DISAVOWAL

Denial

Projection

Rationalization

Fantasy

MAJOR IMAGE DISTORTING (Borderline)

Splitting (other's image)

Splitting (self image)

Projective identification

ACTION

Acting out

Passive aggression

Help-rejecting complaining 
APPENDIX 2: Ethics Certificate 